\title{
The Interactive Effect of Supply Chain Integration on Performance of Intemational Freight Forwarders
}

\author{
Hee Sung Bae*
}

\begin{abstract}
There are two aims of this research: one is to prove the interactive effect of supply chain integration (SCI) on performance and the other is to ascertain gaps in performance among levels of SCI. The population of this research is international freight forwarders and the collected data is used in testing hypotheses through various analytical methods such as factor analysis, Cronbach's alpha, cluster analysis, ANOVA, MANOVA, ANCOVA, post hoc analysis and regression analysis. First, the interaction between internal integration and external integration improves customer performance and financial performance. The forwarders improve internal processes following information acquired from customers and the information is shared with logistics service providers, followed by high performance. Second, gaps in performance among levels of SCI are verified. Managers of the forwarders make strategic decision making on the basis of their recognition of environment and, as a result, the forwarders enjoy different performance.
\end{abstract}

Key Words : Supply chain, Integration, Interaction, Performance, Forwarders

JEL classification : $L 1 \& M 11$

\footnotetext{
* Department of International Trade, Pusan National University, Busan, Republic of Korea. Email: h.s.bae@pusan.ac.kr
} 


\section{Introduction:}

The positive effect of SCI on performance is verified by prior research (Bae, 2012b, 2014; Larson, 1994; Schoenherr and Swink, 2012). SCI is defined as strategic collaboration with departments and partners in corporate processes (Wong et al., 2011). It can be divided into internal integration (II) and external integration (EI). The former can be explained as strategic systems and collaborative responsibility among departments and the latter can be interpreted as information sharing and strategic collaboration among supply chain partners. Almost all of research papers on the relationship between SCI and performance are performed from the viewpoint of manufacturing firms (Green et al., 2012; Tsai et al., 2012). On the other hand, research for SCI from the viewpoint of logistics firms can make possible deeper understanding on the relationship between SCI and performance. Especially, international freight forwarders (IFFs) are general carriers to transport cargoes on behalf of shippers and perform the whole transportation through collaboration with other logistics service providers. From the viewpoint, IFFs provide shippers with services as carriers and play a role as shippers to other service providers. Therefore, research on the relationship between SCI and performance of IFFs can help to understand the relationship between manufacturing firms and logistics firms.

Prior research has investigated the relationship between SCI and performance from various viewpoints. Research on the interactive effect of II and EI on performance has verified synergy effects (Droge et al., 2004; Schoenherr and Swink, 2012). In addition, the positive relationship between II and EI is the basis of the synergy effects (Braunscheidel and Suresh, 2009; Chen et al., 2009; Gimenez, 2006; Gimenez and Ventura, 2005; Salvador et al., 2001; Stank et al., 2001; Schoenherr and Swink, 2012). On the other hand, prior research has ascertained gaps in performance among levels of SCI (Frohlich and Westbrook, 2001; Flynn et al., 2010; Schoenherr and Swink, 2012). Despite the results of prior research, the relationship between SCI and performance has still limitations as follows. First, some prior research did not verify the relationship between the interaction between II and EI and performance (Boon-itt and Wong, 2011; Flynn et al., 2010). Second, gaps in performance among levels of SCI is still indefinite (Gimenez, 2006; Thun, 2010). Therefore, this research has two objectives: one is to prove the interactive effect of SCI on performance and the other is to test gaps in performance among levels of SCI. 


\section{Literature Review}

Prior research has ascertained the relationship between SCI and performance (Aryee et al., 2008; Ghobakhloo et al., 2011; Rajaguru and Matanda, 2009; Richey et al., 2009; Sezen, 2008). In addition, prior research has verified that the interaction between II and EI has a positive effect on performance (Boon-itt and Wong, 2011; Danese and Romano, 2011; Droge et al., 2004; Flynn et al., 2010; Germain and Iyer, 2006; Schoenherr and Swink, 2012). The relationship between SCI and performance is explained by information processing theory. The variance of environment is the cause of the variance of firms. Firms would change internal processes through learning of external information to adapt for the changed environment (Bae et al., 2012). This is connected with minimizing the effect of environment on performance. From the viewpoint, firms can improve performance through the interaction with environment. Environment which firms face means all factors to exist in external areas of firms and, from the viewpoint, suppliers and customers can be treated with environmental factors which have an influence on firms (Flynn et al., 2010). Therefore, firms can achieve high performance through the interaction with suppliers and customers.

On the other hand, prior research has ascertained gaps in performance among levels of SCI (Daugherty et al., 1996; Flynn et al., 2010: Frohlich and Westbrook, 2001). According to Stevens (1989), SCI is developed from inter-functional integration to EI. This is shown in development stages of SCI such as independent operations, inter-functional integration, II and EI (Narasimhan and Kim, 2001). This is the cause of gaps in performance among levels of SCI. Strategic choice theory explains the theoretical basis on gaps in performance among levels of SCI. Firms can adapt to the variance of environment through changing organizations caused by the variance of environment (Chandler, 1962). From the viewpoint, managers should recognize the variance of environment and lead the variance of organizations on the basis of their recognition of environment, followed by high performance (Child, 1974). Therefore, firms need to ascertain their level of SCI at the present time and then they can identify the method of improving performance.

Despite the positive relationship between the interaction between II and EI and performance, prior research has following limitations. First, the causal relationship between the interaction and performance is still indefinite. Many researchers have verified that the interaction has a positive effect on performance (Droge et al., 2004; Schoenherr and Swink, 2012). However, some researchers did not find the positive relationship between the interaction and performance (Boon-itt and Wong, 2011; Flynn et al., 2010). The result means that the relationship between the interaction and performance is unclear. Therefore, 
this research needs to ascertain the causal relationship between the interaction and performance. Second, many researchers have verified the positive relationship between EI and performance (Ghobakhloo et al., 2011; Rai et al., 2006). However, some prior research has stressed the interaction between II and EI on performance (Droge et al., 2004) or the indirect effect of EI by way of II on performance (Stank et al., 2001; Bae, 2012a) rather than the direct effect of EI on performance (Bae, 2011). This means that the direct effect of EI on performance is still indefinite. Therefore, this research needs to test whether the interaction between II and EI has a positive effect on performance. Third, prior research has proved gaps in performance among levels of SCI (Frohlich and Westbrook, 2001; Schoenherr and Swink, 2012). However, it is not clear whether the gaps in performance are come from either levels of SCI or the other performance which has high correlation. In other words, high correlation between sub-variables on performance can distort the result of gaps in performance among levels of SCI. Therefore, this research need to prove gaps in performance among levels of SCI to use multivariate analysis of variance (MANOVA) and need to verify a pure gap in each performance among levels of SCI to use analysis of covariance (ANCOVA).

\section{Research Model and Methodology}

\subsection{Research Model}

To achieve the objectives of this research, a research model is suggested as follows.

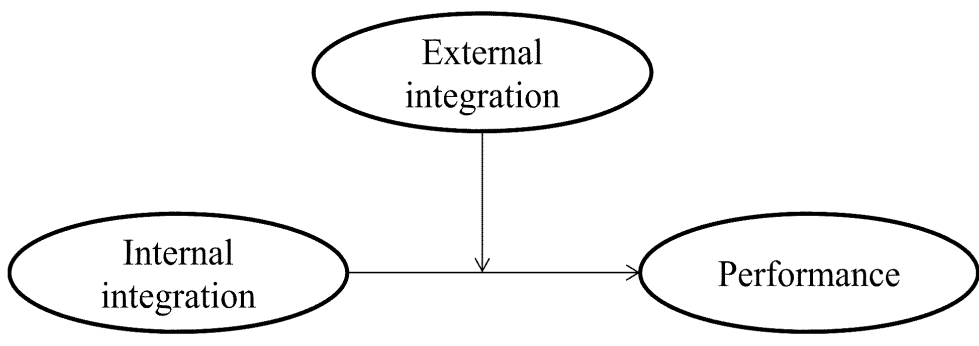

Figure 1.

The Research Model 
Figure 1 shows the moderating effect of EI on the relationship between II and performance. This means that the interaction between II and EI has a positive effect on customer performance (CP) and financial performance (FP). In addition, this research also verifies gaps in performance among levels of SCI. This is to test gaps in CP and FP among the stages of independent operations, the stage of II, the stage of EI and the stage of SCI shown in II and EI. The gaps have an influence on strategic choice of firms to improve performance.

\subsection{Hypotheses}

\subsubsection{The Interactive Effect between Internal and External Integration on Customer Performance}

Firms struggle for integrating activities among functions. In addition, the activities also play an important role in the inter-corporate viewpoint. In particular, the supply chain viewpoint is focused on suppliers and customers as EI as well as II. Integration can be grasped as joint works between departments from the viewpoint of corporate behavior, be regarded as shared culture from the viewpoint of corporate culture and be considered as collaborative relationships from the viewpoint of the relationships between firms. Integration means that supply chain partners perform joint works through adjusting inter-functional activities beyond the boundary of firms for achieving customer needs (Simatupang and Sriharan, 2002). SCI is defined as performing joint works together in supply chains and this means that firms create competitive advantages through performing information sharing, collaborative decision making and benefits sharing with supply chain partners to achieve final customers needs and, consequently, enjoying high performance (Simatupang and Sriharan, 2005). The integration has a direct effect on performance (Min et al., 2005). Firms concentrate resources in core competence and non-core competence is outsourced to supply chain partners. As a result, supply chain participants combine their core competence and compete fiercely with inter-supply chains rather than inter-firms. In this regard, supply chain participants enhance capability of firms through integration with partners and, consequently, achieve high performance (Bae, 2012a). Managers integrate their processes in order to increase value to decline wastes, over delay of works and overlaps (Matopoulus et al., 2007). Integration between firms through integrating processes on the basis of II minimizes cost and does not follow a sacrifice of services. The relationship between the interaction between II and EI and performance was already 
verified by prior research (Flynn et al., 2010; Germain and Iyer, 2006; Schoenherr and Swink, 2012). Therefore, the interaction between II and EI is the cause of CP.

$<\mathrm{H} .1>$ The interactive effect of II and EI improves CP.

\subsubsection{The Interactive Effect of II and EI on FP}

The relationship between the interaction between II and EI and performance can be explained as information processing theory. Environment means all factors to affect firms and to exist in exterior of firms (Lawrence and Lorsch, 1967). Firms should be changed following the variance of environment and, as a result, they can achieve high performance. From the viewpoint, suppliers and customers as supply chain partners are regarded as environmental factors which have an influence on firms (Flynn et al, 2010). Managers acquire information through interaction with them and internal processes are changed by the acquired information, followed by high performance. On the basis of the theoretical background, firms collaborate with supply chain partners to achieve high performance and the collaboration has a synergy effect on performance through the interaction with II (Bae, 2012a). In other words, the interactive effect of II and EI is larger than the independent effects of them on performance. Integration between supply chain partners is the cause of structuring efficient processes through mutual information sharing. Information sharing among supply chain partners is the basis of which IFFs grasp customer needs through collaboration with shippers and the information concerned with the needs is the cause of structuring efficient service processes because it is shared with logistics service providers. Firms which structure the efficient service processes achieve high performance in the market. From the viewpoint, the relationship between the interaction between II and EI and performance is verified by prior research (Boon-itt and Wong, 2011; Danese and Romano, 2011; Droge et al., 2004). Therefore, the interaction between II and EI is connected with high FP.

$<$ H. $2>$ The interactive effect of II and EI improves FP.

\subsubsection{A Gap in CP among Levels of SCI}

Prior research has ascertained that SCI reflects corporate strategic orientation at the present time and, as a result, firms enjoy different performance (Flynn et al., 2010; Frohlich and Westbrook, 2001; Schoenherr and Swink, 2012). This can be explained by strategic 
choice theory. The theory explains that a strategy is decided by decision making of managers. Managers learn external environment and then decide a strategy following the perceived variance of environment. From the viewpoint, managers become moderators to connect environment with firms. Therefore, managers' recognition of environment lead the variance of firms and this is the basis of gaps in performance among firms.

Firms choose and perform various strategies to enhance performance. In this regard, SCI is one of strategies which firms could choose. If there is environmental uncertainty, managers choose EI to acquire information in external environment and then carry out II to disseminate the information in internal processes (Wong et al., 2011). Firms, through II, structure superior customer service and, in addition, provide customers with superior services through sharing customer information with suppliers (Guimaraes et al., 2002). The superior services enhance customer performance. Prior research has ascertained that firms which achieve a high level of SCI enjoy high performance (Daugherty et al., 1996; Flynn et al., 2010; Frohlich and Westbrook, 2001; Gimenez, 2006; Gustin et al., 1995; Kim, 2006; Saeed et al., 2011). Therefore, this research proposes a following hypothesis.

$<$ H. $3>$ If firms have a high level of SCI, they achieve high CP.

\subsubsection{A Gap in FP among Levels of SCI}

Strategic choice theory explained as above illustrates the relationship between levels of SCI and performance improvement. The theory can be also applied to the relationship between levels of SCI and FP as well as CP (Ragatz et al., 2002). Firms ascertain their supply chain strategy on the basis of their recognition of environment and, as a result, make strategic choice for performance improvement. Firms which recognize environmental uncertainty enhance EI to acquire opportunities and information in external environment and, consequently, achieve supply chain effectiveness through collaboration with suppliers and customers. On the other hand, firms which recognize environmental stability focus on II following static environment and, consequently, attain efficiency in internal processes. From the viewpoint, firms remove overlaps and inefficiencies in the whole processes through II and EI, followed by high performance. This explanation is connected with the results of prior research (Daugherty et al., 1996; Flynn et al., 2010; Frohlich and Westbrook, 2001; Gimenez, 2006; Gustin et al., 1995; Kim, 2006; Saeed et al., 2011). Therefore, this research proposes a following hypothesis. 
$<$ H. 4> If firms have a high level of SCI, they achieve high FP.

\subsection{Data Collection and Analytical Methods}

The population of this research is IFFs and questionnaires were answered by them. They don't have a means of transportation and are general carriers which have responsible for whole transportation of cargoes on behalf of shippers. In addition, they carry out whole transportation to collaborate with liners, loading/unloading firms, warehouse operators, customs brokers and inland transporters. In this regard, they play a role of carriers from the viewpoint of shippers and have a position of shippers from the viewpoint of substantial logistics service providers. For this reason, this research investigated IFFs as the population and the sample frame is a membership list of the Korean International Freight Forwarder Association. In addition, a survey was performed to all members of the association. Before the survey, the researcher contacted the members by telephone and asked whether they want to respond to a questionnaire. Only if they answered to participate in the survey, the researcher sent the questionnaire to them by their favorite method such as mail, email, telephone, fax or personal visit. The staff of management or sales department answered to the questionnaire. They are corresponded with the objectives of this research because they have performed substantial works with other departments and supply chain partners. The survey was performed from July 2011 to September 2011 and 115 questionnaires were collected. 112 data were used in the analysis because three of them had serious problems. Non-response bias was tested by the method recommended by Armstrong and Overton (1977). The method is that collected data is classified into four groups in arrived order and if there is a gap in responses between a first group and a last group, this means that non-response bias is doubted. As a result of the analysis, there was no gap in responses between the groups.

This research used various analytical methods for testing hypotheses. First, validity of the collected data was verified by factor analysis. If there is below 0.6 in a factor loading coefficient, over 0.6 of the coefficient in over two variables or below 1.0 in eigenvalue, the item is removed. Reliability was tested by Cronbach's alpha. If a Cronbach's alpha coefficient is over 0.6, there is no problem in reliability (Nunnally, 1978). Second, the correlation between variables was proved by correlation analysis, which has three aims. First, the correlation coefficient between independent variables should be low. If there is the high coefficient, multicollinearity is doubted. Second, the correlation coefficient between independent and dependent variables should be high. This means that the former explain the latter very well. Third, the high correlation between dependent variables means 
that the mutual effect between dependent variables can be doubted and this is the cause of ANCOVA. For this reason, researchers should treat the other variables with covariate excluding a dependent variable to be tested by ANCOVA and can verify a pure gap in a dependent variable among clusters. Third, the relationship between the interaction between II and EI and performance was tested by cluster analysis, ANOVA and regression analysis. The first classifies EI into a high cluster and a low cluster. The second proves a gap in the two clusters. The third analyzes the causal links between II and performance on the basis of the two clusters. If the effect of II on performance in a high cluster is significant and $\mathrm{R}$-square of a high cluster is higher than one of a low cluster, the moderating effect of EI on the relationship between II and performance is verified. Forth, gaps in performance among levels of SCI was analyzed by cluster analysis, ANOVA, MANOVA, ANCOVA and post hoc analysis (Scheffe test). MANOVA has four preconditions. Independence among clusters is verified by cluster analysis and ANOVA. Equality of error variance is proved by a covariance of matrix. A normal distribution is ascertained by Kolmogorve-Smironv test. Homoscedasticity is tested by Levene's test. If there are no problems in above four preconditions, gaps in performance among levels of SCI can be tested by MANOVA. MANOVA is the analytical method to prove gaps in dependent variables among clusters if dependent variables are over two. However, the imitation of the method is not to test substantial gaps in dependent variables among clusters. For this reason, post hoc analysis shows substantial gaps in dependent variables among clusters. This research used Scheffe test of various analytical methods because it can minimize the type II error. In addition, the researcher tested a pure gap in performance among clusters to use ANCOVA. If there are over two dependent variables, the result of ANOVA could have the type I error. In other words, the result of ANOVA cannot verify whether gaps in a dependent variable among clusters are based on either clusters or the other dependent variable if there is high correlation between dependent variables. For this reason, ANCOVA treats covariate with the other dependent variable which has high correlation with a dependent variable and proves a pure gap in a dependent variable among clusters.

\section{The Results of the Empirical Tests}

\subsection{The General Characteristics of the Responding Firms}

Before testing the hypotheses, this research investigates the general characteristics of the responding firms. 
Table 1.

The General Characteristics of the Responding Firms

\begin{tabular}{c|c|c|c}
\hline $\begin{array}{c}\text { Annual turnover } \\
\text { (US a million) }\end{array}$ & n (\%) & Year of foundation & $\mathbf{n ~ ( \% )}$ \\
\hline & & Before 1990 & $8(7.1)$ \\
Below 0.1 & $6(5.4)$ & $1991-2000$ & $32(28.6)$ \\
$0.1-0.5$ & $33(29.5)$ & $2001-2010$ & $29(25.9)$ \\
$0.5-1.0$ & $21(18.6)$ & $2010-$ present & $10(8.9)$ \\
$1.0-5.0$ & $7(6.3)$ & No answer & $33(29.5)$ \\
\cline { 2 - 4 } Over 5.0 & $2(1.8)$ & The number of employees & $\mathrm{n}(\%)$ \\
\cline { 2 - 4 } No answer & $43(38.4)$ & Below 10 & $57(50.9)$ \\
& & $11-20$ & $20(17.8)$ \\
& $112(100)$ & Over 20 & $6(5.4)$ \\
\hline Total & & No answer & $29(25.9)$ \\
\hline
\end{tabular}

As shown in Table 1, there are the low levels of the annual turnover of the responding firms. The reasons are that they have not fixed assets and are general carriers on behalf of shippers. They provide shippers with proper international logistics processes through collaboration with logistics service providers. For this reason, they have not fixed assets. In addition, this is another reason that their main works are consolidation of cargoes and accessory services. There are 32 firms founded in 1990s which is the largest in the year of foundation. In addition, the number of employees shows 57 firms in below 10. The results mean that almost IFFs are small and medium size firms.

\subsection{The Result of Reliability and Validity Tests}

Before testing the hypotheses, this research analyzes validity and reliability of measuring items and the result is as follows.

\section{Table 2.}

The Result of Reliability and Validity Tests on Items

\begin{tabular}{|c|c|c|c|c|}
\hline Items & \multicolumn{2}{|c|}{ Factor Lloading } & $\begin{array}{l}\text { Validity \& } \\
\text { Reliability }\end{array}$ & $\begin{array}{l}\text { KMO \& } \\
\text { Bartlett }\end{array}$ \\
\hline $\begin{array}{l}\text { Internal integration (Stank et al., 2001) } \\
\text { II } 1 \text {. An integrated database and access method } \\
\text { II } 2 \text {. Effective sharing of operational information } \\
\text { internally }\end{array}$ & $\underline{0.748}$ & $\begin{array}{l}0.439 \\
0.501\end{array}$ & $\begin{array}{c}\mathrm{C}=0.919 \\
\mathrm{E}=4.069 \\
\% \mathrm{~V}= \\
40.693\end{array}$ & $\begin{array}{c}\mathrm{KMO}= \\
0.870 \\
\text { Chi-square } \\
=871.882\end{array}$ \\
\hline
\end{tabular}




\begin{tabular}{|c|c|c|c|c|}
\hline Items & \multicolumn{2}{|c|}{ Factor Lloading } & $\begin{array}{l}\text { Validity \& } \\
\text { Reliability }\end{array}$ & $\begin{array}{l}\text { KMO \& } \\
\text { Bartlett }\end{array}$ \\
\hline $\begin{array}{l}\text { II 3. Ability to share standardized information } \\
\text { II } 4 \text {. Objective feedback to employees } \\
\text { II 5. Reward systems to encourage integration }\end{array}$ & $\begin{array}{l}0.767 \\
0.873 \\
0.786 \\
\end{array}$ & $\begin{array}{l}0.442 \\
0.125 \\
0.314\end{array}$ & & \\
\hline $\begin{array}{l}\text { External integration (Stank et al., 2001) } \\
\text { EI 1. Effective sharing of operation information } \\
\text { with partners } \\
\text { EI 2. Supply chain performance systems } \\
\text { EI 3. Improved performance by integrating } \\
\text { operations with partners } \\
\text { EI 4. Operational flexibility through collaboration } \\
\text { with partners } \\
\text { EI 5. To learn best practices of partners (deleted) }\end{array}$ & $\begin{array}{l}0.376 \\
0.267 \\
0.206 \\
0.513 \\
0.694\end{array}$ & $\begin{array}{l}\underline{\mathbf{0 . 8 3 5}} \\
\underline{\mathbf{0 . 8 9 4}} \\
\underline{\mathbf{0 . 6 8 2}} \\
\underline{0.292}\end{array}$ & $\begin{array}{c}\mathrm{C}=0.856 \\
\mathrm{E}=3.196 \\
\% \mathrm{~V}= \\
31.959\end{array}$ & $\begin{array}{c}\mathrm{df}=45 \\
\mathrm{p}=0.000\end{array}$ \\
\hline $\begin{array}{l}\text { Customer performance (Rosenzweig et al., 2003) } \\
\text { CP 1. The increased rate of market share } \\
\text { CP 2. The increased rate of customer gathering } \\
\text { CP 3. The increased rate of customer maintenance } \\
\text { CP 4. The increased rate of customer profitability } \\
\text { (deleted) }\end{array}$ & $\frac{0.840}{\underline{0.828}}$ & $\begin{array}{l}0.404 \\
0.455 \\
0.467 \\
0.676\end{array}$ & $\begin{array}{c}\mathrm{C}=0.933 \\
\mathrm{E}=3.105 \\
\% \mathrm{~V}= \\
44.362\end{array}$ & $\begin{array}{c}\mathrm{KMO}= \\
0.916 \\
\text { Chi-square } \\
=892.852\end{array}$ \\
\hline $\begin{array}{l}\text { Financial performance (Stock et al., 2000) } \\
\text { FP 1. The increased rate of investment profitability } \\
\text { FP 2. The increased rate of revenue } \\
\text { FP 3. The increased rate of sales profitability }\end{array}$ & $\begin{array}{l}0.438 \\
0.532 \\
0.392\end{array}$ & $\frac{0.831}{0.763}$ & $\begin{array}{c}\mathrm{C}=0.930 \\
\mathrm{E}=3.052 \\
\% \mathrm{~V}= \\
43.594\end{array}$ & $\begin{array}{c}\mathrm{df}=21 \\
\mathrm{p}=0.000\end{array}$ \\
\hline
\end{tabular}

Notes) $\mathrm{C}=$ Chronbach's alpha; $\mathrm{E}=$ eigenvalue; $\% \mathrm{~V}=$ percentage of variance explained; $\mathrm{df}=$ degree of freedom

As shown in Table 2, II is explained by five items and factor loading coefficients are shown over 0.6. EI is also explained by four items and the coefficients are shown over 0.6. All results concerned with SCI are satisfied with the criteria and, as a result, there are no problems in reliability and validity. However, EI 5 is removed because of factor cross loading. $\mathrm{CP}$ is explained by three items and factor loading coefficients are shown over 0.6 . FP is also explained by three items and the coefficients are shown over 0.6. All results concerned with performance are satisfied with the criteria and, as a result, there are no problems in reliability and validity. However, CP 4 is removed because of factor cross loading. 
Table 3.

The Result of Correlation Analysis

\begin{tabular}{c|c|c|c|c|c|c}
\hline Variables & Average & S.D. & II & EI & CP & FP \\
\hline II & 4.704 & 1.308 & 1.000 & & & \\
\hline EI & 4.757 & 1.139 & $0.770^{* *}$ & 1.000 & & \\
\hline CP & 4.753 & 1.214 & $0.492^{* *}$ & $0.536^{* *}$ & 1.000 & \\
\hline FP & 4.646 & 1.341 & $0.464^{* *}$ & $0.464^{* *}$ & $0.838^{* *}$ & 1.000 \\
\hline
\end{tabular}

Notes) ${ }^{* *}: \mathrm{p}<0.01 ;$ S.D. $=$ standard deviation

As shown in Table 3, there are high levels of the correlation coefficients between II and EI. This means that multicollinearity is doubted. The result of multicollinearity analysis shows 0.406 in tolerance (criterion: > 0.1) and 2.461 in VIF (criterion: <10.0) and, as a result, there is no problem in multicollinearity. There are high levels of the correlation coefficients between independent variables and dependent variables and this means that the former explain the latter very well. In addition, there is a high level of the correlation coefficient between dependent variables (0.838). This is the basis of ANCOVA for confirming a pure gap in performance among clusters.

\subsection{Tests of Hypotheses}

The moderating effect of EI on the relationship between II and performance is verified by cluster analysis and simple regression analysis. Cluster analysis classifies the sample firms into two clusters on the basis of EI. Cluster 2 shows $5.64(n=61)$ in an average of EI and cluster 1 shows $3.70(n=51)$ in an average of EI. As a result of ANOVA, the two clusters are proved as different clusters $(\mathrm{F}=288.331, \mathrm{p}=0.000)$.

\section{Table 4.}

The Interactive Effect of II and EI on Performance

\begin{tabular}{c|c|c|c|c|c|c}
\hline \multirow{2}{*}{ Path } & \multicolumn{3}{|c|}{ Cluster 1 (3.70) } & \multicolumn{3}{c}{ Cluster 2 (5.64) } \\
\cline { 2 - 7 } & $\mathbf{t}$ & $\mathbf{F}$ & $\mathbf{R 2}$ & $\mathbf{t}$ & $\mathbf{F}$ & $\mathbf{R}$ \\
\hline $\mathrm{II} \rightarrow \mathrm{CP}$ & 0.640 & 0.410 & -0.012 & $4.467^{* *}$ & $19.956^{* *}$ & 0.240 \\
\hline $\mathrm{II} \rightarrow \mathrm{FP}$ & 1.218 & 1.484 & 0.010 & $3.056^{* *}$ & $9.337^{* *}$ & 0.122 \\
\hline
\end{tabular}

Note) $* *: p<0.01$ 
As shown in Table 4, the interaction between II and EI improves performance (H. 1 and H. 2 supported). Cluster 1 (low EI) has low $t$ value and F value on R-square is not significant. On the other hand, cluster 2 (high EI) has high t value and F value is significant. Compared on the basis of R-square, cluster 2 is much higher than cluster 1 . Therefore, the result verifies that the interaction between II and $\mathrm{EI}$ improves $\mathrm{CP}$ and $\mathrm{FP}$.

Next is to test gaps in performance among levels of SCI. SCI is divided into the stage of independent operations, the stage of II, the stage of EI and the stage of SCI composited by II and EI. II is divided into four clusters and the average of each cluster is 3.06 in cluster $1(\mathrm{n}=27), 6.10$ in cluster $2(\mathrm{n}=33), 4.49$ in cluster $3(\mathrm{n}=47)$ and 6.36 in cluster $4(\mathrm{n}=5)$ and the result of ANOVA is 151.439 in F value $(\mathrm{p}<0.000)$. In addition, EI is also divided into four clusters and the average of each cluster is 3.36 in cluster 1, 6.08 in cluster 2, 4.64 in cluster 3 and 4.72 in cluster 4 and the result of ANOVA is 122.663 in F value $(p<0.000)$. From the viewpoint, cluster 1 is the stage of independent operations (the lowest averages in II and EI), cluster 4 is the stage of II (the highest II but low EI), cluster 3 is the stage of EI (high EI but low II) and cluster 2 is the stage of SCI (high II and the highest EI). Gaps in $\mathrm{CP}$ and FP among levels of SCI are proved by MANOVA. There are four preconditions of MANOVA: independence among clusters, equality of error variance, a normal distribution and homoscedasticity. The first is verified by the results of ANOVA as above ( $\mathrm{F}=151.439$ in II and $\mathrm{F}=122.663$ in EI) and the results show independence among clusters. The second is ascertained by a covariance of matrix among clusters and the result represents that they are equality ( $\mathrm{p}=0.061, \mathrm{~F}=1.817$ ). The third is proved by Kolmogrove-Smirnov test and the result shows that there are no problems ( $\mathrm{p}=0.467$ in II, 0.352 in EI, 0.151 in CP and 0.131 on FP). The last is tested by Leneve's test and the result shows that there are no problems $(p=0.413$ in $\mathrm{CP}$ and 0.220 in FP).

\section{Table 5.}

The Result of MANOVA

\begin{tabular}{c|c|c|c|c|c|c}
\hline Source & $\begin{array}{c}\text { Dependent } \\
\text { Variable }\end{array}$ & $\begin{array}{c}\text { Type III } \\
\text { Sum of } \\
\text { Square }\end{array}$ & df & $\begin{array}{c}\text { Mean } \\
\text { Square }\end{array}$ & F & P \\
\hline $\begin{array}{c}\text { Corrected } \\
\text { Model }\end{array}$ & CP & $51.818 \mathrm{a}$ & 3 & 17.273 & 16.703 & 0.000 \\
FP & $47.229 \mathrm{~b}$ & 3 & 15.743 & 11.157 & 0.000 \\
\hline Intercept & CP & 1260.100 & 1 & 1260.100 & 1218.570 & 0.000 \\
\hline FP & 1160.681 & 1 & 1160.681 & 822.589 & 0.000 \\
SCI & FP & 51.818 & 3 & 17.273 & 16.703 & 0.000 \\
\hline
\end{tabular}




\begin{tabular}{|c|c|c|c|c|c|c|}
\hline Source & $\begin{array}{c}\text { Dependent } \\
\text { Variable }\end{array}$ & $\begin{array}{l}\text { Type III } \\
\text { Sum of } \\
\text { Square }\end{array}$ & df & $\begin{array}{l}\text { Mean } \\
\text { Square }\end{array}$ & F & $\mathbf{P}$ \\
\hline Error & $\begin{array}{l}\mathrm{CP} \\
\mathrm{FP}\end{array}$ & $\begin{array}{l}111.681 \\
152.389\end{array}$ & $\begin{array}{l}108 \\
108\end{array}$ & $\begin{array}{l}1.034 \\
1.411\end{array}$ & - & - \\
\hline Total & $\begin{array}{l}\mathrm{CP} \\
\mathrm{FP}\end{array}$ & $\begin{array}{l}2693.667 \\
2617.000\end{array}$ & $\begin{array}{l}112 \\
112\end{array}$ & - & - & - \\
\hline $\begin{array}{c}\text { Corrected } \\
\text { Total }\end{array}$ & $\begin{array}{l}\mathrm{CP} \\
\mathrm{FP}\end{array}$ & $\begin{array}{l}163.499 \\
199.618\end{array}$ & $\begin{array}{l}111 \\
111\end{array}$ & - & - & - \\
\hline
\end{tabular}

Notes) a: R2 $=0.317(\operatorname{adjR} 2=0.298), b: R 2=0.237(\operatorname{adjR} 2=0.215)$

As shown in Table 5, gaps in CP and FP among levels of SCI are proved (F=16.703 in $\mathrm{CP}$ and $\mathrm{F}=11.157$ in $\mathrm{FP})$. This result means that there are gaps in performance among levels of SCI (H. 3 and H.4 supported). There are high R-squares such as 0.317 in CP and 0.237 in FP. This means that gaps in performance among levels of SCI are definite. However, the limitation of MANOVA is that the result does not show substantial gaps in performance among levels of SCI. Therefore, post hoc analysis is performed.

Table 6.

The Results of Post Hoc Analysis (Scheffe Test)

\begin{tabular}{|c|c|c|c|c|c|c|c|}
\hline \multirow{2}{*}{ Cluster } & \multirow{2}{*}{$\mathbf{n}$} & \multicolumn{2}{|c|}{ Groups of CP } & \multirow{2}{*}{ Cluster } & \multirow{2}{*}{$\mathbf{n}$} & \multicolumn{2}{|c|}{ Groups of FP } \\
\hline & & 1 & 2 & & & 1 & 2 \\
\hline 1 & 27 & & & 1 & 27 & & \\
\hline 3 & 47 & $\begin{array}{l}3.963 \\
4504\end{array}$ & & 4 & 5 & $\begin{array}{l}3.852 \\
4.400\end{array}$ & 4.400 \\
\hline 4 & 5 & & 4.867 & 3 & 47 & 4475 & 4.475 \\
\hline 2 & 33 & & 5.737 & 2 & 33 & & 5.576 \\
\hline $\mathrm{p}$ & - & 0.147 & 0.173 & $\mathrm{p}$ & - & 0.593 & 0.085 \\
\hline
\end{tabular}

As shown in Table 6, CP is divided into two groups and $\mathrm{p}$ values of the two groups are not significant. This means that clusters of each group are regarded as the same group. Cluster 1 as the stage of an independent operations has the lowest CP in an average. In addition, cluster 2 as the stage of SCI has the highest CP in an average. The two clusters are included in different groups. This reflects the fact that if IFFs are included in the stage of II or EI, their CP is higher than one of IFFs included in the stage of independent operations. In addition, if they are included in the stage of SCI, they achieve the highest CP. Similarly, FP 
is divided into two groups. Group 1 includes cluster 1 (independent operations), cluster 4 (II) and cluster 3 (EI) and group 2 includes cluster 4, cluster 3 and cluster 2 (SCI). On the basis of $\mathrm{p}$ value, clusters in each group are ascertained as a group in an average of FP in statistically. This can be also explained as cluster 1 has the lowest FP and cluster 2 has the highest FP and they are different groups. This is equal to the result of CP.

This research ascertained the high correlation coefficient between CP and FP in Table 3 (0.838). In this regard, this research needs to prove whether a gap in performance is based on either levels of SCI or the other performance which has high correlation. This can be proved by ANCOVA. As a precondition of ANCOVA, Levene's test to equality of error variance on $\mathrm{CP}$ has no problem $(\mathrm{p}=0.394)$.

\section{Table 7.}

The Result of ANCOVA on CP

\begin{tabular}{c|c|c|c|c|c}
\hline Source & $\begin{array}{c}\text { Type III Sum } \\
\text { of Square }\end{array}$ & df & Mean Square & F & p \\
\hline $\begin{array}{c}\text { Corrected } \\
\text { model }\end{array}$ & $120.652 \mathrm{a}$ & 4 & 30.163 & 75.324 & 0.000 \\
\hline Intercept & 18.427 & 1 & 18.427 & 46.018 & 0.000 \\
\hline FP & 68.833 & 1 & 68.833 & 171.894 & 0.000 \\
\hline CP & 5.787 & 3 & 1.929 & 4.817 & 0.003 \\
\hline Error & 42.847 & 107 & 0.400 & - & - \\
\hline Total & 2693.667 & 112 & - & - & - \\
\hline $\begin{array}{c}\text { Corrected } \\
\text { Total }\end{array}$ & 163.499 & 111 & - & - & - \\
\hline
\end{tabular}

Note) $\mathrm{R} 2=0.738(\operatorname{adjR} 2=0.728)$

As shown in Table 7, there is a gap in CP as a dependent variable among levels of SCI $(p=0.003)$. FP as covariate is a gap among the levels of SCI $(p=0.000)$. For this reason, a gap in CP among levels of SCI does not be affected by FP. In addition, R-square shows 0.738 and this means that a gap in CP among the levels of SCI is definite. Next is to test a gap in FP among levels of SCI. As a precondition of ANCOVA, Levene's test to equality of error variance on FP has no problem $(p=0.770)$. 
Table 8.

The Result of ANOCA on FP

\begin{tabular}{c|c|c|c|c|c}
\hline Source & $\begin{array}{c}\text { Type III Sum } \\
\text { of Square }\end{array}$ & df & Mean Square & F & p \\
\hline $\begin{array}{c}\text { Corrected } \\
\text { model }\end{array}$ & $141.153 \mathrm{a}$ & 4 & 35.288 & 64.582 & 0.000 \\
\hline Intercept & 0.187 & 1 & 0.187 & 0.342 & 0.560 \\
\hline CP & 93.924 & 1 & 93.924 & 171.894 & 0.000 \\
\hline FP & 0.913 & 3 & 0.304 & 0.557 & 0.645 \\
\hline Error & 58.465 & 107 & 0.546 & - & - \\
\hline Total & 2617.000 & 112 & - & - & - \\
\hline Corrected & 199.618 & 111 & - & - & - \\
Total & & &
\end{tabular}

Note) $R 2=0.707$ (adj R2 $=0.696$ )

As shown in Table 8, a gap in CP as covariate among levels of SCI is significant $(\mathrm{p}=0.000)$. However, a gap in FP as a dependent variance among levels of SCI is not significant ( $\mathrm{p}=0.645)$. This means that there is no gap in FP among levels of SCI. In other words, a gap in FP among levels of SCI in the result of MANOVA is regarded as the effect of $\mathrm{CP}$. This result is regarded as the cause that $\mathrm{CP}$ which has high correlation with $\mathrm{FP}$ is included in the model. Therefore, the result of MANOVA is not a pure gap in FP among levels of SCI.

\subsection{Discussion of the Results}

The results of this research can be translated as follows. First, the results show that the interaction between II and EI improves CP and FP. The relationship between the interaction and performance can be explained by information processing theory. IFFs can treat shippers and logistics service providers with external environment (Flynn et al., 2010). They can grasp requirements of customers through interaction with environment and this is the cause of structuring efficient internal processes. Because the information is shared with logistics service providers as supply chain partners, IFFs can provide shippers with efficient international logistics services. As a result, IFFs improve market share, customer gathering and customer maintenance and also enhance investment profitability, revenue and sales profitability through the interaction between II and EI. The effect of the interaction between 
II and EI on performance is already verified by prior research (Boon-itt and Wong, 2011; Danese and Romano, 2011; Droge et al., 2004; Flynn et al., 2010; Germain and Iyer, 2006; Schoenherr and Swink, 2012). This can provide justification to the results of this research.

Second, the results of this research verify gaps in performance among levels of SCI. This can be explained by strategic choice theory. IFFs choose a different strategy following the variance of external environment. In this regard, managers connect environment with IFFs. From the viewpoint, managers' recognition of environment is the basis of strategic decision making. In addition, IFFs choose an external-oriented strategy like EI if they recognize environmental uncertainty, whereas choose an internal-oriented strategy like II if they recognize stable environment (Porter, 1980). From the viewpoint, IFFs make strategic decision on the basis of recognition on external environment and, as a result, they enjoy different performance. Therefore, IFFs which achieve a high level of SCI can enjoy high CP and FP. This result is the same as the results of prior research (Daugherty et al., 1996; Flynn et al., 2010; Frohlich and Westbrook, 2001; Gimenez, 2006; Gustin et al., 1995; Kim, 2006; Saeed et al., 2011). This can provide justification to the results of this research.

\section{Conclusion}

This research has two objectives: one is to verify the positive effect of the interaction between II and EI on performance and the other is to prove gaps in performance among levels of SCI. To achieve the objectives, various analytical methods are used. On the basis of the collected data, reliability is ascertained by Cronbach' alpha and validity is verified by factor analysis. The hypotheses of this research are proved by cluster analysis, ANOVA, MANOVA, ANCOVA, post hoc analysis and regression analysis. Theoretical implications of the results are already explained and managerial implications, limitations and future research directions are as follows.

The results of this research provide various managerial implications. First, the interaction between II and EI enhances performance. From the viewpoint, managers should maintain close relationships with shippers as well as logistics service providers such as liners, loading/unloading firms, container terminal operators, bonded transporters, customs brokers and bonded warehouse operators. In particular, IFFs are mediators to connect shippers with logistics service providers and should share customer needs acquired from shippers with all departments from the internal viewpoint and logistics service providers from the external viewpoint. This information sharing through SCI enhances CP and FP. Second, gaps in performance among levels of SCI are verified. The result explains that IFFs 
achieve high performance compared with independent operations if they achieve II or EI. In addition, they enjoy the highest performance if they achieve SCI. The result explains that IFFs should approach to SCI from the strategic viewpoint. In other words, IFFs should use SCI for enhancing CP and FP. Therefore, IFFs grasp their level of SCI at the present time first and then they can improve performance through strategic decision making.

Despite the implications, this research has following limitations. First, levels of SCI are not clearly divided in the result of post hoc analysis. Cluster 4 (the stage of II) is included in two groups in $\mathrm{CP}$ and cluster 4 and cluster 3 (the stage of EI) are included in two groups in FP. This has not an effect on the results of this research. However, additional research for indefinite classification among levels of SCI is required. Second, the result of ANCOVA ascertained that a gap in FP among levels of SCI is affected by CP. The high correlation between CP and FP is the cause of this. However, a gap in CP among the levels of SCI is not affect by FP. Therefore, additional research is required for testing the cause of the phenomenon.

\section{Acknowledgement}

This work was supported by the National Research Foundation of Korea Grant funded by the Korean Government. [NRF-2013S1A5B5A07044812] 


\section{References}

Armstrong, J.S. and Overton, T.S. (1977) "Estimating Nonresponse Bias in Mail Surveys", Journal of Marketing Research, 14(3), 396-402.

Aryee, G., Naim M. and Lalwani, C. (2008) "Supply Chain Integration using a Maturity Scale", Journal of Manufacturing Technology Management, 19(5), 559-575.

Bae, H. (2011) "The Relationships between Environment, Integration and Performance in Supply Chain Contexts", The Asian Journal of Shipping and Logistics, 27(1), 61-90.

Bae, H. (2012a) "The Influencing Factors of Logistics Integration and Customer Service Performance for Value Creation of Port Logistics Firms", The Asian Journal of Shipping and Logistics, 28(3), 345-368.

Bae, H. (2012b) "An Analysis of Gaps in Performance among Development Stages of Integration in SCM", Journal of International Logistics and Trade, 10(3), 85-104.

Bae, H., Lee, Y., and Lee, W. (2012), "The Effect of Innovation and Market Orientation on Customer Service for Customer Clearance Firms in the International Logistics Processes: the Analysis of Direct, Indirect, Causal Effects and Moderating effects between Variables", Journal of International Logistics and Trade, 10(1), 109-133.

Bae, H. (2014) Investigating the Effect of Environmental Uncertainty on Supply Chain Collaboration and Operational Performance, Ph.D. thesis, the University of Hull.

Boon-itt, S. and Wong, C.Y. (2011) "The Interactions between Internal and External Integration and Their Combined Effects on Operational Performance", POMS 22nd Conference Reno, USA, Paper No. 020-0296, 1-20.

Bowersox, D.J., Closs, D.J. and Cooper, M.B. (2002) Supply Chain Logistics Management, McGrow Hill.

Braunscheidel, M.J. and Suresh, N.C. (2009) “The Organizational Antecedents of a Firm's Supply Chain Agility for Risk Mitigation and Response", Journal of Operations Management, 27(2), 119-140. 
Chandler, Jr. A.D. (1962) Strategy and Structure, Doubleday, Garden City: New York.

Chen, H., Daugherty, P.J. and Roath, A.S. (2009) "Defining and Operationalizing Supply Chain Process Integration", Journal of Business Logistics, 30(1), 63-84.

Child, J. (1974) "Managerial and Organizational Factors Associated with Company Performance - Part I", Journal of Management Studies, 11(3), 175-189.

Danese, P. and Romano, P. (2011) "Supply Chain Integration and Efficiency Performance: A Study on the Interactions between Customer and Supplier Integration", Supply Chain Management: An International Journal, 16(4), 220-230.

Daugherty, P.J., Ellinger, A.E. and Gustin, C.M. (1996) "Integrated Logistics: Achieving Logistics Performance Improvements", Supply Chain Management: an International Journal, 1(3), 25-33.

Droge, C., Jayaram, J. and Vickery, S.K. (2004) "The Effects of Internal versus External Integration Practices on Time-based Performance and Overall Firm Performance", Journal of Operations Management, 22, 557-573.

Flynn, B.B., Huo, B. and Zhao, X. (2010) "The Impact of Supply Chain Integration on Performance: A Contingency and Configuration Approach", Journal of Operations Management, 28, 58-71.

Frohlich, M.T. and Westbrook, R. (2001) "Arcs of Integration: An International Study of Supply Chain Strategies", Journal of Operations Management, 19, 185-200.

Germain, R. and Iyer, K.N.S. (2006) "The Interaction of Internal and Downstream Integration and Its Association with Performance", Journal of Business Logistics, 27(2), 29-51.

Ghobakhloo, M., Sabouri, M.S., Hong, T.S. and Amirizadeh, K. (2011) "Electronic Commerce-Enabled Supply Chain Process Integration and Business Value", Journal of Systems and Information Technology, 13(4), 344-368. 
Gimenez, C. and Ventura, E. (2005) "Logistics-Production, Logistics-Marketing and External integration: Their Impact on Performance", International Journal of Operations and Production Management, 25(1), 231-249.

Gimenez, C. (2006) "Logistics Integration Processes in the Food Industry", International Journal of Physical Distribution and Logistics Management, 36(3), 231-249.

Green, K.W., Zelbst, P.J., Bhadauria, V.S. and Meacham, J. (2012) "Do Environmental Collaboration and Monitoring enhance Organizational Performance?", Industrial Management and Data Systems, 112(2), 186-205.

Guimaraes, T., Cook, D. and Natarajan, N. (2002), "Exploring the Importance of Business Clockspeed as a Moderator for Determinants of Supplier Network Performance", Decision Sciences, 33(4), 629-644.

Gustin, C.M., Daugherty, P.J. and Stank, T.P. (1995) "The Effect of Information Availability on Logistics Integration", Journal of Business Logistics, 16(1), 1-21.

Kim, S.W. (2006) "The Effect of Supply Chain Integration on the Alignment between Corporate Competitive Capability and Supply chain Operational Capability", International Journal of Operations and Production Management, 26(10), 1084-1107.

Larson, P.D. (1994) “An Empirical Study of Inter-organizational Functional Integration and Total Cost”, Journal of Business Logistics, 15(1), 153-169.

Lawrence, P.R. and Lorsch, J.W. (1967) Organization and Environment: Managing Differentiation and Integration, Boston: Harvard University Press.

Matopoulos, A., Vlachopoulou, M., Manthou, V. and Manos, B. (2007) "A Conceptual Framework for Supply Chain Collaboration: Empirical Evidence from the Agri-food Industry", Supply Chain Management: An International Journal, 12(3), $177-186$.

Min, S., Roath, A.S., Daugherty, P.J., Genchev, S.E., Chen, H., Arndt, D. and Richey, R.G. (2005) "Supply chain collaboration: what's happening?", The International Journal of Logistics Management, 16(2), 237-256. 
Narasimhan, R. and Kim, S.W. (2001) "Information System Utilization Strategy for Supply Chain Integration", Journal of Business Logistics, 22(2), 51-75.

Nunnally, J. (1978) Psychometric Theory, New York: McGrow-Hill.

Rai, A., Patnayakuni, R. and Seth, N. (2006) "Firm Performance Impacts of Digitally Enabled Supply Chain Integration Capabilities”, MIS Quarterly, 30(2), 225-246.

Rajaguru, R. and Matanda, M.J. (2009) "Influence of Inter-organizational Integration on Business Performance", Journal of Enterprise Information Management, 22(4), 456-467.

Ragatz, G.L., Hannfield, R.B. and Petersen, K.J. (2002) "Benefits Associated with Supplier Integration into New Product Development under Conditions of Technology Uncertainty", Journal of Business Research, 55, 389-400.

Richey, Jr., R.G., Chen, H., Upreti, R., Fawcett, S.E. and Adams, F.G. (2009) "The Moderating Role of Barriers on the Relationship between Drivers to Supply Chain Integration and Firm Performance", International Journal of Physical Distribution and Logistics Management, 39(10), 826-840.

Saeed, K.A., Malhotra, M.K. and Grover, V. (2011) "Interorganizational System Characteristics and Supply Chain Integration: An Empirical Assessment", Decision Sciences, 42(1), 7-41.

Salvador, F., Forza, C., Rungtusantham, M. and Choi, T.Y. (2001) "Supply Chain Interactions and Time-Related Performances", International Journal of Operations and Production Management, 21(4), 461-475.

Schoenherr, T. and Swink, M. (2012) "Revisiting the Arcs of Integration: Cross-Validations and Extensions", Journal of Operations Management, 30, 99-115.

Sezen, B. (2008) "Relative Effects of Design, Integration and Information Sharing on Supply Chain Performance", Supply Chain Management: An International Journal, 13(3), 233-240. 
Simatupang, T.M. and Sridharan, R. (2002) "The Collaborative Supply Chain", International Journal of Logistics Management, 13(1), 15-30.

Simatupang, T.M. and Sridharan, R. (2005) "The Collaboration Index: A Measure for Supply Chain Collaboration", International Journal of Physical Distribution and Logistics Management, 35(1), 44-62.

Stank, T.P., Keller, S.B. and Daugherty, P.J. (2001) "Supply Chain Collaboration and Logistical Service Performance", Journal of Business Logistics, 22(1), 29-48.

Stevens, G.C. (1989) "Integrating the Supply Chain", International Journal of Physical Distribution and Logistics Management, 19(8), 3-8.

Thun, J.-H. (2010) "Angles of Integration: An Empirical Analysis of The Alignment of Internet-based Information Technology and Global Supply Chain Integration", Journal of Supply Chain Management, 46(2), 30-44.

Tsai, K.-H., Tsai, M.-L. and Wang, J.-C. (2012) "Supplier Collaboration and New Product Performance: A Contingency Model”, Industrial Management and Data Systems, 112(2), 268-289.

Wong, C.Y., Boon-itt, S. and Wong, C.W.Y. (2011) "The Contingency Effects of Environmental Uncertainty on the Relationship between Supply Chain Integration and Operational Performance", Journal of Operation Management, 29, 604-615. 